\title{
Molecular epidemiology of mosquito-borne viruses at the China-Myanmar border: discovery of a potential epidemic focus of Japanese encephalitis
}

Yuan Fang ${ }^{1,2}$, Xi-Shang Li ${ }^{3}$, Wei Zhang ${ }^{4}$, Jing-Bo Xue ${ }^{1,2}$, Jia-Zhi Wang ${ }^{3}$, Shou-Qin Yin ${ }^{4}$, Sheng-Guo Li ${ }^{3}$, Xin-He Li ${ }^{3}$ and Yi Zhang ${ }^{1,2^{*}}$

\begin{abstract}
Background: Mosquito-based arbovirus surveillance can serve as an early warning in evaluating the status of mosquito-borne virus prevalence and thus prevent local outbreaks. Although Tengchong County in Yunnan Province - which borders Myanmar - is abundant and diverse in mosquitoes, very few mosquito-based arbovirus investigations have been conducted in the recent decade. Herein, this study aims to evaluate the presence and the diffusion of mosquito-borne pathogens, currently prevalent in this region.

Methods: We collected 9486 mosquitoes, representing eight species, with Culex tritaeniorhynchus and Anopheles sinensis as the dominant species, during high mosquito activity seasons (July-October) in Tengchong, in 2018. Samples collected from 342 pools were tested using reverse-transcription PCR to determine the species, distribution, and infection rates of virus and parasite, and further analyze their genotypes, phylogenetic relationships, infection rate, and potential pathogenicity.
\end{abstract}

Results: Fifteen Japanese encephalitis virus (JEV) strains from CX. tritaeniorhynchus pools were detected. Seven strains of insect-specific flaviviruses (ISFVs), including two Aedes flavivirus (AeFV) and Yunnan Culex flavivirus strains each, one Culex theileri flavivirus, Yamadai flavivirus (YDFV) and Anopheles-associated flavivirus (AAFV) strains each were detected in Aedes albopictus, CX. tritaeniorhynchus, CX. vagans, CX. pseudovihnui, and An. sinensis pools, respectively. The whole-genome was successfully amplified in one strain of JEV and AeFV each. Phylogenetic analysis using the $E$ gene placed all the newly detected JEV strains into the Gl-b genotype. They showed highly nucleotide identities, and were most closely related to the strain detected in Tengchong in 2010. The comparison of the E protein of JEV strains and vaccine-derived strain, showed six amino residue differences. The bias-corrected maximum likelihood estimation values (and 95\% confidence interval) for JEV in CX. tritaeniorhynchus collected in Tengchong in 2018 were 2.4 (1.4-3.9).

Conclusions: A potential Japanese encephalitis epidemic focus with the abundance of host mosquitoes and high JEV infection rate was observed in Tengchong. In addition, at least five species of ISFVs co-circulate in this area. This

\footnotetext{
*Correspondence: zhangyi@nipd.chinacdc.cn

${ }^{1}$ National Institute of Parasitic Diseases, Chinese Center for Disease

Control and Prevention (Chinese Center for Tropical Diseases Research);

NHC Key Laboratory of Parasite and Vector Biology; WHO Collaborating

Centre for Tropical Diseases; National Center for International Research

on Tropical Diseases, Shanghai, China

Full list of author information is available at the end of the article
}

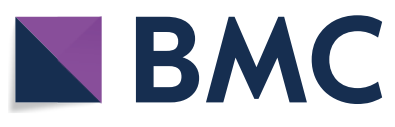

(c) The Author(s) 2021. Open Access This article is licensed under a Creative Commons Attribution 4.0 International License, which permits use, sharing, adaptation, distribution and reproduction in any medium or format, as long as you give appropriate credit to the original author(s) and the source, provide a link to the Creative Commons licence, and indicate if changes were made. The images or other third party material in this article are included in the article's Creative Commons licence, unless indicated otherwise in a credit line to the material. If material is not included in the article's Creative Commons licence and your intended use is not permitted by statutory regulation or exceeds the permitted use, you will need to obtain permission directly from the copyright holder. To view a copy of this licence, visit http://creativecommons.org/licenses/by/4.0/. The Creative Commons Public Domain Dedication waiver (http://creativeco mmons.org/publicdomain/zero/1.0/) applies to the data made available in this article, unless otherwise stated in a credit line to the data. 
study highlights the importance of widespread and sustained mosquito-based arbovirus surveillance in local areas to prevent the transmission of JEV, and other emerging/re-emerging mosquito-borne pathogens.

Keywords: Culex tritaeniorhynchus, Insect-specific flavivirus, Mosquito-borne diseases, Tengchong, China, SA14-14-2

\section{Background}

The prevalence of mosquito-borne viruses is rising steeply with increasing frequency of international trade and travel. Because of the existence of vectors, imported mosquito-borne diseases may cause local infections and even outbreaks in areas with no previous record of a specific mosquito-borne pathogen detection.

The majority of China is located in warm-tropical, subtropical, and tropical zones, which are suitable for the breeding of mosquitoes. Mosquitoes which transmit clinically relevant viruses in China include Aedes albopictus, Culex tritaeniorhynchus, and Anopheles sinensis as the dominant species in several areas, mainly transmitting dengue virus (DENV), Japanese encephalitis virus (JEV), and Plasmodium spp., respectively. Dengue outbreaks occurred in Yunnan (2013, [1]), Guangdong (2014, [2]), Fujian (2016, [3]), and Zhejiang (2017, [4]) provinces throughout the last decades. Despite the implementation and expansion of Japanese encephalitis (JE) vaccination program for children in China since the 1970s, and 2008, respectively, there were occasional incidents of JE recurrence and outbreaks in Shanxi (2006, [5]), Hubei (2009-2010, [6]), Shandong (2013, [7]), and Gansu (2018, [8]) provinces. The increase in adult JE cases is a characteristic of JE outbreaks in recent years. China has applied to the World Health Organization for the certification of malaria eradication in December 2020 [9], and thus monitoring local malaria cases and preventing secondary cases would be of focus in the future. China was a traditionally Chikungunya-free country, until 2010, when the first chikungunya outbreak was reported in Guangdong that resulted in 173 clinical cases [10]. The Zika virus (ZIKV) was prevalent in South America in 2016 [11], in the same year, it was detected in mosquitoes in Guizhou $[12,13]$ and Yunnan [14], indicating the circulation of ZIKV in China before it was widespread.

Due to the geological position and complex natural climate, the mosquitoes in the Yunnan Province are abundant and diversified $[15,16]$. Clinically relevant mosquitoes, $C x$. tritaeniorhynchus and An. sinensis are active at night and are the dominant species among domestic animals and humans; while, the DENV vector, Ae. albopictus is active during the day especially in bamboo and wood groves [17]. Mosquito-borne pathogens, including Plasmodium spp., JEV, DENV, ZIKV, Chikungunya virus, Sindbis virus, Banna virus, and several other viruses, have been detected in Yunnan [18-23], which borders with Myanmar, Laos, and Vietnam. Mosquitoborne disease prevention and control in Yunnan is even more complicated and severe for the constant influx of imported cases from neighboring countries [24-26]. The DENV outbreak in Yunnan Province in 2013 was suspected to be induced by the dissemination of previously sporadically reported imported cases of DENV in bordering areas of Yunnan [27]. Tengchong County, adjacent to Myanmar, was once a malaria-unstable region due to the frequent migration of workers from Myanmar [28, 29]. Since 2013, no local cases of malaria have been reported in Tengchong [28,30]. Moreover, owing to the timely verification of imported malaria cases and prompt investigation on identified malaria foci and further disposal within 7 days after index case reporting, the imported ones have declined since then $[29,31]$. Besides parasites, JEV from Cx. tritaeniorhynchus, An. sinensis, Armigeres subalbatus, and Getah virus from Cx. pseudovishnui have been isolated from field-collected mosquitoes in 2007 [32, 33]. Tengchong was the second highest county for imported infectious diseases among 25 bordering counties of the Yunnan Province from 2013 to 2017. Dengue fever and malaria were the primary imported diseases in the adjacent areas of Yunnan Province, with an occupation of $62.1 \%$ and $36.6 \%$, respectively [31]. Thus, with the wide distribution and abundance of $C x$. tritaeniorhynchus, An. sinensis, and several other clinically relevant mosquitoes in Tengchong [34], it is necessary to document the species diversity, distribution, intensity, genotype variation, and pathogenicity of circulating pathogens in mosquitoes for the development and implementation of disease prevention and control strategies. However, to our knowledge, only a few surveys of arbovirus and parasites in mosquitoes have been reported in Tengchong in the last decade. Therefore, in this study, we used mosquito samples from routine surveillance in Tengchong in 2018 to determine the diversity, geographic distribution and infection rates of Plasmodium spp., alphaviruses, flaviviruses, and orthobunyaviruses in mosquitoes, and further analyze their genotypes, phylogenetic relationships, sources of importation, and potential pathogenicity.

\section{Methods}

\section{Survey site}

Tengchong lies in the west of the Yunnan Province, with a $148 \mathrm{~km}$ border to Myanmar. It is located at a longitude of $98^{\circ} 05^{\prime}-98^{\circ} 45^{\prime}$ degrees east, and a latitude of 
$24^{\circ} 38^{\prime}-25^{\circ} 52^{\prime}$ degrees north. The altitude is between 930 and $3780 \mathrm{~m}$, decreasing from northwest to southeast. In Tengchong, which is situated in the subtropical monsoon climate, the annual average temperature is $14.9^{\circ} \mathrm{C}(-4.2-$ $30.5^{\circ} \mathrm{C}$ ) and the rainfall averages $1531 \mathrm{~mm}$ a year, with a mean relative humidity of $77 \%$.

\section{Sampling}

A surveillance program for detecting the distribution and diversity of vector pathogens in field-caught mosquitoes was conducted in Tengchong from July to October 2018. Both ultraviolet light traps (Wuhan Lucky Star Environmental Protection Technology Co., Ltd., Wuhan, China) and labor hour methods were applied to catch adult mosquitoes in five sentinel sites, twice a month, ten days apart. The sentinel sites covered environments of several ecological areas, including the residential area, school, hospital, green space, and livestock farm. The light traps were hung one hour before sunset (7:00 PM) until one hour after sunrise (7:30 AM) to collect the mosquitoes overnight. The labor hour method [35] was used to catch adult mosquitoes in indoor habitats using a mouth aspirator for $15 \mathrm{~min}, 1 \mathrm{~h}$ following sunset.

The survey on the immature growth stage of Aedes mosquitoes was conducted once a month in a fixed community, as a sentinel site. Water-holding containers, including tires, rainwater drums, discarded cans, house plants, and other artificial containers closely associated with human dwellings and outdoor environment, were examined for the presence of aedine larvae and pupae. The Breteau index (BI) was calculated by the number of positive containers per 100 houses inspected [36]. The aedine larvae and pupae were brought to the laboratory and reared until the emergence of adults.

All the mosquito samples were identified using morphological characteristics according to the national and provincial key $[15,37]$ under ice bath conditions, and pooled by species, sex, collection date, method and location. Each pool consisted of 1-50 female individuals and was stored at $-80{ }^{\circ} \mathrm{C}$ until further pathogen detection. High resolution satellite image from Gaofen-1 satellite at a resolution of $16 \mathrm{~m}$, was obtained for Tengchong from China Center for Resources Satellite Data and Application (www.cresda.com, Accessed 13 March 2021). Collection sites of each method are shown in Fig. 1, and a map was generated using ArcGIS 10.1 ArcMap software (ESRI, Redlands, CA, USA).
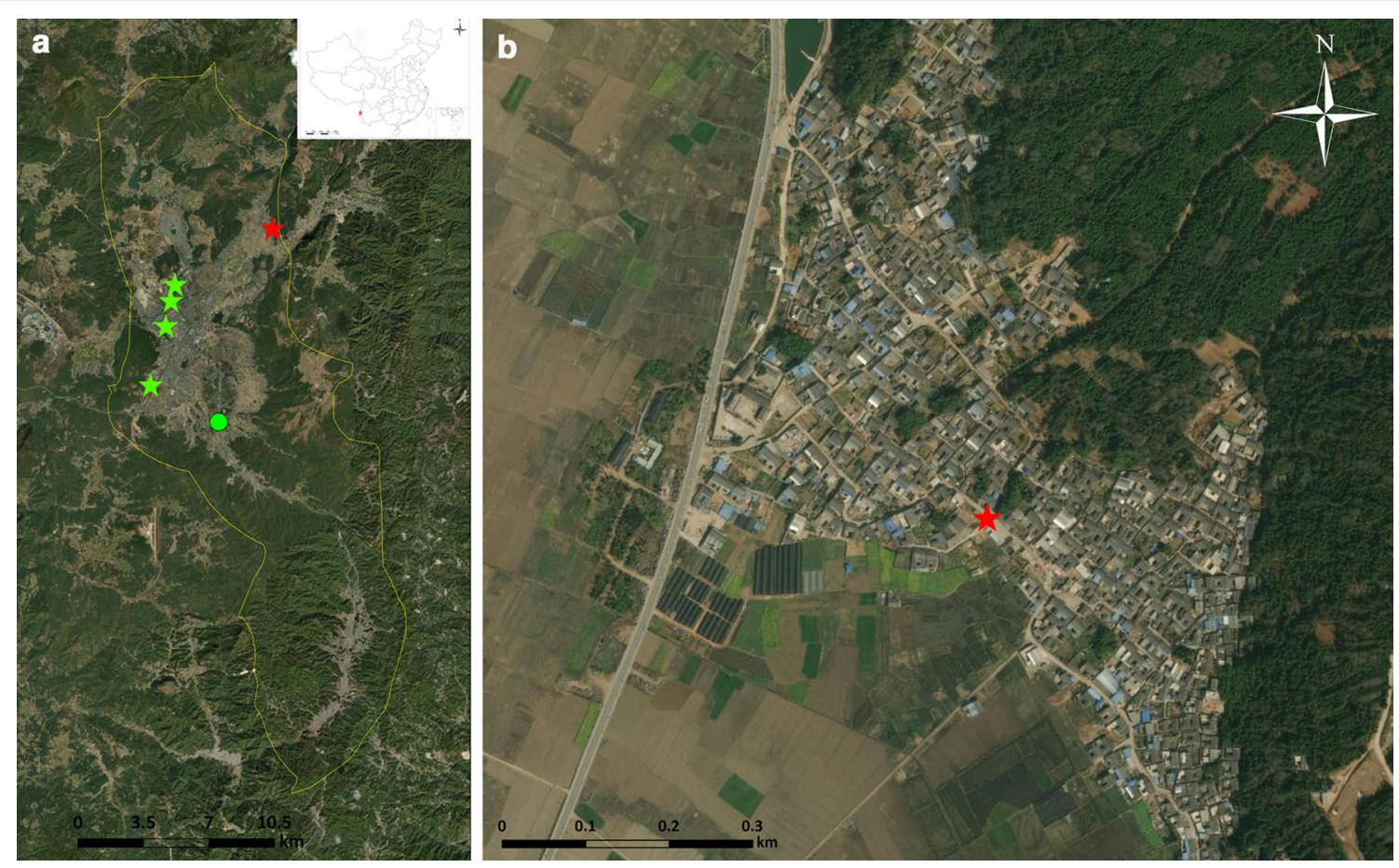

Fig. 1 Map of mosquito collection sites for pathogen detection in 2018 in Tengchong. a Mosquito collection sites, where the light trap method, labor hour method (represented with stars), and the sentinel site for Breteau index monitoring (represented with a circle) were used. The red-filled star represents the site of Japanese encephalitis virus (JEV) detection. b Aerial view of Fuyu village with the settlement and sampling site. The location of the cattle farm is marked with a red-filled star 


\section{Nucleic acid extraction and polymerase chain reaction (PCR)}

RNA was extracted from all pools of mosquitoes using the MagNA Pure 96 System (Roche, Basel, Switzerland) as previously described [38], yielding a final product of $50 \mu \mathrm{l} /$ pool. First-strand cDNA was synthesized by reverse-transcription (RT) using a Takara PrimeScript RT Reagent Kit with gDNA Eraser (Takara Bio, Shiga, Japan). The mosquito "house-keeping" gene, $18 S$ rRNA gene was amplified using the RT products with primer set $18 \mathrm{~S} 417$ and 18S920c [39] to assess the integrity of RNA. Nested multiplex PCR was carried out to detect the presence of four species of Plasmodium, including P. falciparum, $P$. vivax, $P$. malariae, and $P$. ovale, as described by Li et al. [40]. Flavivirus was amplified using the primer pair PF1S and PF2R-bis [41], and the universal flavivirus primer set cFD2 and MAMD, cFD2 and FS778 by hemi-nested PCR [42], targeting the partial NS5 gene. Primer sets JEV-Ef/ JEV-Er [43], and prMF/prMR [44] were used to amplify the $E$ and $p r M$ genes for further genotype identification. Alphaviruses and orthobunyaviruses in mosquito samples were amplified using primer sets $\alpha 6533 f / \alpha 6999 \mathrm{c}$ [45] and $\mathrm{BCS} 82 \mathrm{C} / \mathrm{BCS} 332 \mathrm{~V}$ [46], respectively. PCR products were visualized on 1 or $2 \%$ (depending on the length of the amplification fragments) agarose gels with Goldview in $0.5 \times$ Tris-acetate-EDTA buffer. Positive products were purified, cloned and sequenced by Sanger sequencing.

\section{Whole-genome sequencing}

For further analyses on the molecular characteristics of the virus, the Primer Premier 5.0 (Premier Biosoft International, Palo Alto, CA, USA) was applied to design primers to amplify the complete genome of JEV and Aedes flavivirus (AeFV). The sequencing of JEV wholegenome was performed using the genomic sequence of the local DH10M978 isolate (GenBank Access No. KT229573) as reference. For sequencing the full-length AeFV, primers were designed using the Thailand strain Bangkok (KJ741266). The resulting PCR products were sent for Sanger sequencing and used to design subsequent primers.

\section{Phylogenetic analysis}

Sequences of PCR products were compared with those deposited in the GenBank database using the BLAST program [47]. Multiple sequence alignments were generated with fragments of relevant flavivirus NS5 ( $260 \mathrm{bp})$, JEV prM ( 580 bp), and JEV $E(\sim 1500$ bp) genes, retrieved from GenBank, and sequences obtained in this study, using ClustalW2 [48] with default settings, which were manually adjusted if necessary. Neighbor-joining (NJ) trees were established following Kimura's twoparameter (K2P) distance model [49] with 1000 bootstrap replicates using MEGA v7.0 software [50]. Based on the Akaike information criterion, the best-fit model for the alignment was determined using Modeltest 3.7 [51], in cooperation with PAUP*v.4.0b10 [52]. Consequently, calculation of the maximum likelihood (ML) and Bayesian likelihood trees was completed under the GTR $+\mathrm{I}+\mathrm{G}$ model for NS5 and E genes, whereas the TrN $+\mathrm{G}$ model was used for the $p r M$ gene. The ML tree was constructed using MEGA v.7.0 software [50], with 1000 bootstrap replicates. The Bayesian tree was constructed using MrBayes v.3.2.1 [53], run for 10 million generations, with the first $25 \%$ of generations discarded as burn-in. The trees were unrooted to provide the least biased topology and visualized using Figtree v.1.4.2 (http://tree.bio.ed.ac. uk/software/figtree/).

\section{Comparison of virus deduced amino acid sequences}

The $E$ gene of JEVs sequenced in this study were translated into amino acid sequences and aligned with other representative (homologous) sequences retrieved from GenBank using MEGA v7.0. Amino acid substitutions unique to the newly sequenced strains, and those different from SA14-14-2 vaccine sequence were observed. The attenuated live vaccine SA14-14-2 strain was derived from JEV GIII [54]. In addition, the whole-genome of JEV was translated into amino acid sequences and compared with the closest sequence and the SA14-14-2 strain.

\section{Infection rate calculation}

The size of the pools of collected mosquitoes varied considerably; therefore, infection rates were calculated using bias-corrected maximum likelihood estimation (MLE) and minimum infection rate (MIR) using the Excel addin PooledInfRate v.4 statistical software package [55]. The rates are expressed as the number of infected mosquitoes per 1000 collected mosquitoes.

\section{Results \\ Mosquito diversity and virus detection from samples Mosquito diversity and density}

A total of 9486 mosquitoes, representing eight species were collected in Tengchong during mosquito activity season in 2018, and all the samples in 354 pools were tested for the presence of mosquito-borne pathogens. Among them, Cx. tritaeniorhynchus was the dominant species (6490/149 pools), accounted for $68.41 \%$, followed by $A n$. sinensis (29.25\%, 2775/145 pools), Cx. pipiens quinquefasciatus $(1.22 \%, 116 / 42$ pools), $C x$. bitaeniorhynchus (0.33\%, 3/3 pools), Cx. pseudovihnui (0.52\%, 50/2 pools), Cx. vagans (0.02\%, 2/1 pool), Ae. albopictus $(0.45 \%, 43 / 7$ pools), and Ar. subalbatus $(0.07 \%$, $7 / 5$ pools). The BI was $0.60,0.85,0.63$, and 0.24 in July, 
August, September, and October in Tengchong in 2018, respectively.

\section{Molecular identification of mosquito-borne viruses}

The integrity of RNA extracted from the mosquito pools was tested by the amplification of the $18 S$ rRNA. This amplification was successful in all the 354 pools. In further pathogen detection, 22 flavivirus strains were recovered by the successful amplification of the partial NS5 gene. According to the phylogenetic analysis (Fig. 2), JEVs were present in 15 pools of Cx. tritaeniorhynchus. The prM and $E$ genes were successfully amplified in 12

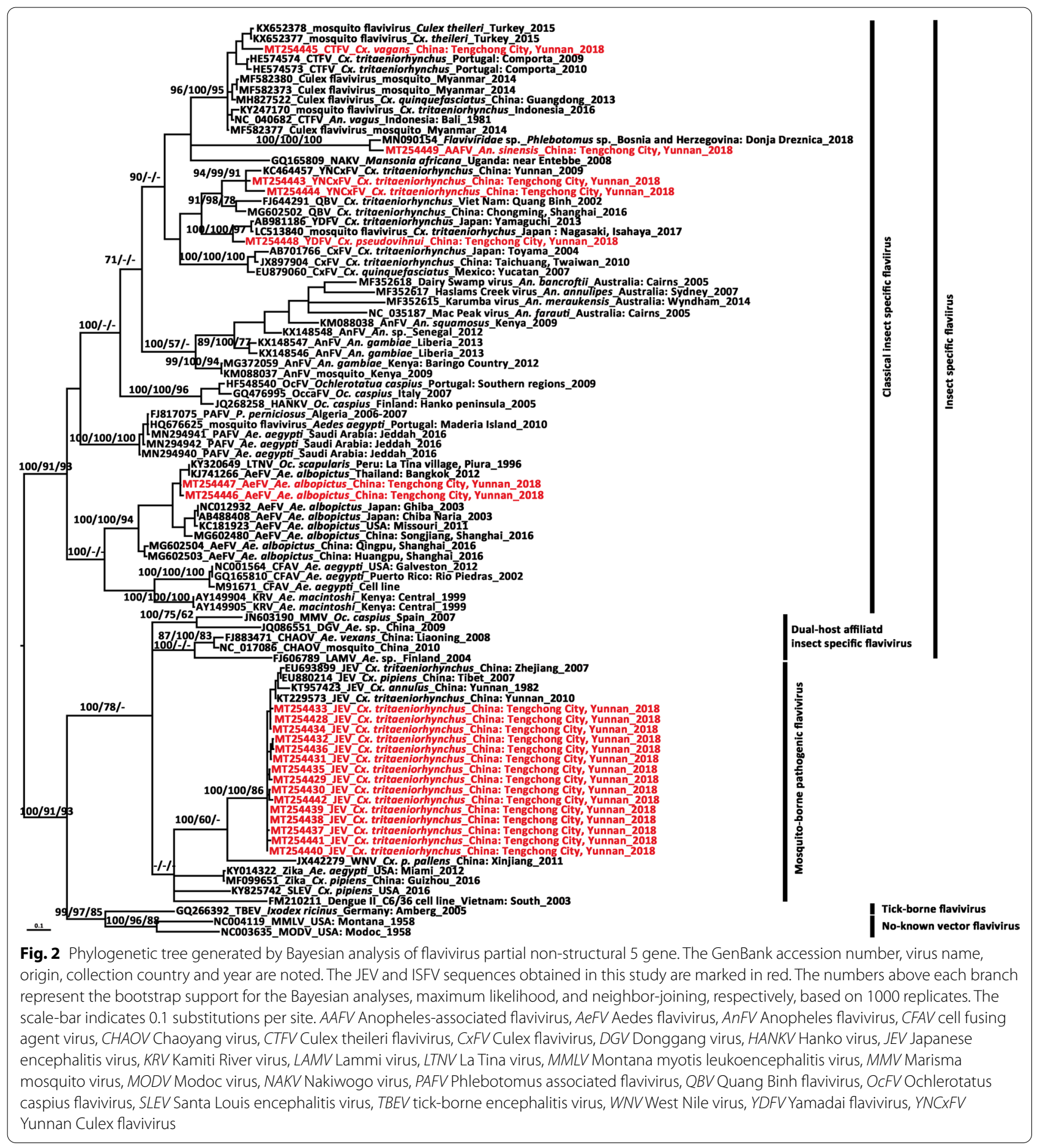




\section{(See figure on next page.)}

Fig. 3 Phylogenetic tree generated by Bayesian analysis of Japanese encephalitis virus envelop gene sequences. The GenBank accession number, origin, collection country and year of each strain are noted. The JEV sequences obtained in this study are marked in red. The numbers above each branch represent the bootstrap support of the Bayesian analyses, maximum likelihood, and neighbor-joining, respectively, based on 1000 replicates. The scale-bar indicates 0.05 substitutions per site. Sequences shaded tan represent the Gl-a genotype, those shaded rose-brown represent the GI-b genotype, those shaded sky blue represent the Gll genotype, those shaded khaki represent the Glll genotype, those shaded aquamarine represent the GIV genotype, and those shaded purple represent the GV genotype

and 9 of the 15 JEV-positive pools, respectively. Phylogenetic analyses (Fig. 3) indicated that GI-b was the only genotype detected among samples collected in Tengchong in 2018. The species name, collection information, host species and GenBank accession numbers of JEV and insect-specific flavivirus (ISFV) strains obtained in this study, are shown in Table 1. No sequences ascribable to the PCR target were obtained using the PCR for alphaviral and orthobunyaviral genomes. Moreover, no Plasmodium spp. was found in this study. Particularly, in the partial NS5 gene amplification, a flavivirus-positive pool of An. sinensis showed $93.5 \%$ similarity to the $12 \mathrm{R}$ (MN090154) strain of Flaviviridae sp. from Phlebotomus sp. collected in Bosnia and Herzegovina in 2018. This putative new ISFV had not been named yet. We designated the new virus as Anopheles-associated flavivirus (AAFV) tentatively.

\section{The whole genome of JEV and AeFV}

The length of the whole-genome of the newly detected JEV (TC4E10_18-9E-Y-T-Cxt-Y-5-11 strain MT254426) was $10953 \mathrm{bp}$, with an open reading frame coding for 3432 amino acids flanked by 96 and 573 nucleotides at the 5'UTR and 3'UTR ends, respectively. The complete genome was amplified using a total of 11 pairs of overlapping primers (Additional file 1: Table S1). The length of the whole-genome of newly detected AeFV (TC4E2_189E-Y-T-Aea-B-JM-1 strain, MT254427) was 10998 bp, with an open reading frame coding for 3341 amino acids flanked by 96 and 909 nucleotides at the 5'UTR and 3'UTR ends, respectively. The complete genome was amplified using a total of ten pairs of overlapping primers (Additional file 1: Table S2).

\section{Molecular characterization and phylogenetic analysis of JEV}

\section{Phylogenetic analyses on NS5, prM, and E gene of JEV.}

The phylogenetic tree based on the NS5 gene (Fig. 2) showed that the genus of Flaviviridae contains four main clusters, including mosquito-borne flaviviruses (the majority are pathogenic), tick-borne flaviviruses, noknown vector flaviviruses and classical ISFVs. The ISFVs are divided into classical ISFVs and dual-host affiliated ISFVs. The dual-host affiliated ISFVs are phylogenetically close to the mosquito-borne pathogenic flaviviruses than the clade of classical flaviviruses. Fifteen flavivirus-positive sequences, belonging to the mosquito-borne flavivirus, were clustered in the JEV clade, and the other seven sequences were scattered in classical ISFV clusters.

The topologies of the trees produced from the JEV $E$ (Fig. 3) and $p r M$ genes (Additional file 1Fig. S1) identified five major clades corresponding to genotypes I, II, III, IV and V. Moreover, GI was composed of two distinct clades, representing the two sub-genotypes, GI-a and GI-b. Based on the supporting values of the three phylogenetic trees, for the majority of lineages, the Bayesian method resulted in relatively higher bootstrap values than the ML and NJ methods. Henceforth, the Bayesian tree is presented here with the supporting values of all the three methods. The $\operatorname{prM}(580 \mathrm{nt})$ tree showed lower bootstrap values but displayed a topology consistent with that obtained with the $E$ gene sequence (1500 nt).

The $p r M$ gene sequences of the JEV strains from Tengchong County showed high levels of similarity with each other at the nucleotide (range: 97.8-100\%) and amino acid (range: $95.9-100 \%$ ) levels, but a lower homology to the vaccine SA14-14-2 strain $(87.8-88.7 \%$ at the nucleotide level and $94.3-96.9 \%$ at the amino acid level). For the $E$ gene, $98.9-100 \%$ nucleotide sequence identity and 99.6-100\% amino acid sequence identity was observed among the newly detected Tengchong strains, while they were $87.2 \%-87.8 \%$ and $96.7 \%-97.0 \%$ similar regarding the nucleotide and amino acid levels when compared with the vaccine strain SA14-14-2. Amino acid substitutions unique to the newly sequenced strains and those different from their closest sequences are shown in Additional file 1: Table S3. In the $E$ gene tree (Fig. 3), the newly obtained strains fell into the GI-b cluster and were most closely related to the strain obtained in Tengchong in 2010 (DH10M978 strain, KT229573), but far from several strains circulated in Tengchong in 2007.

\section{Comparison on deduced amino acid of E protein among JEV strains}

Deduced amino acid differences in E protein sequences were aligned for comparison among the newly sequenced strains and the vaccine strain (SA14-14-2) currently used in China. Six amino acid residues in the newly detected Shanghai JEV strains differed from those in the SA14-14-2-derived strain (SA14): E123 (Ser $\rightarrow$ Asn), 


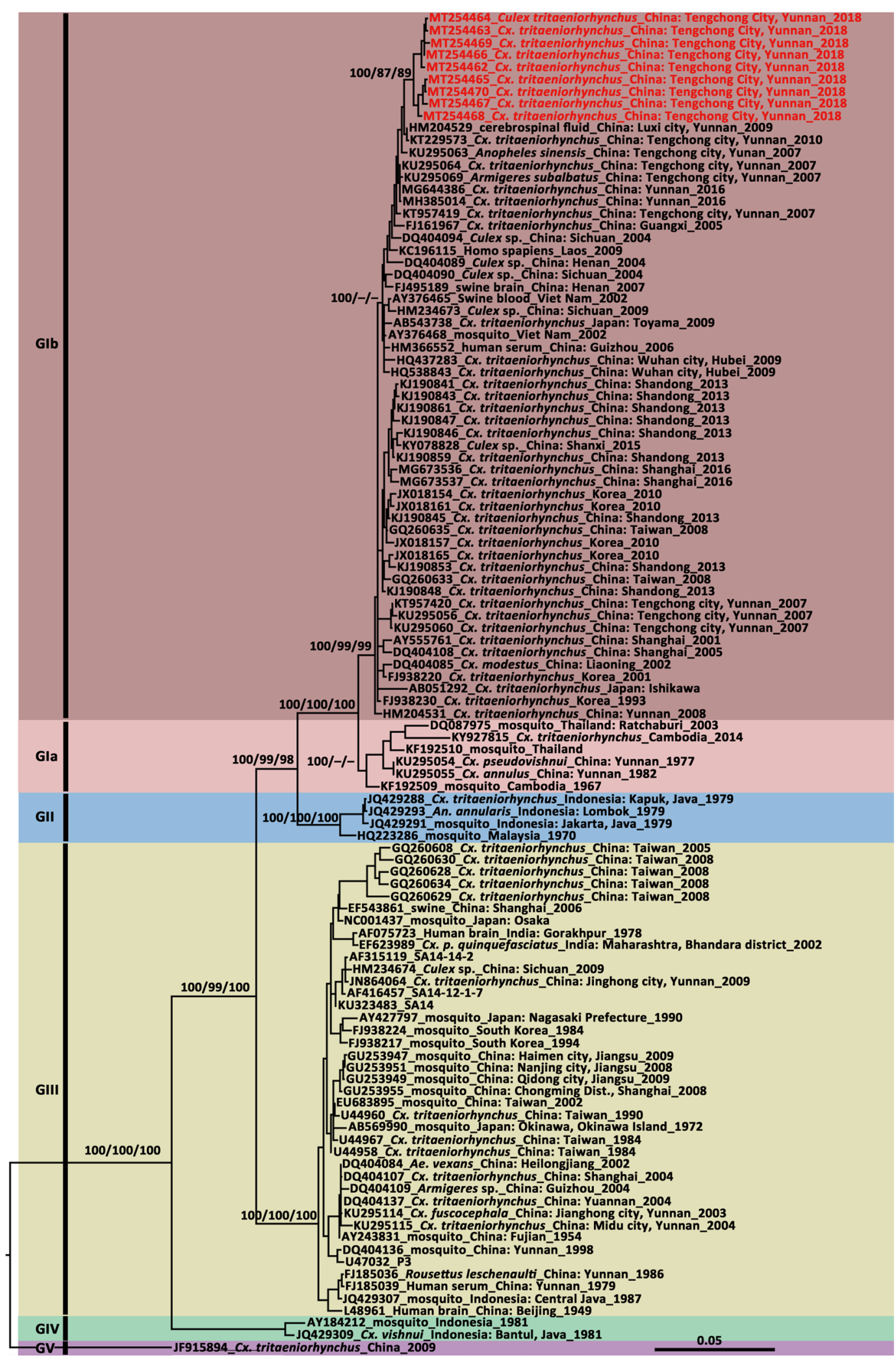


Table 1 Details of flavivirus strains detected from mosquitoes, captured in Tengchong from July to October in 2018

\begin{tabular}{|c|c|c|c|c|c|c|c|c|}
\hline \multirow[t]{2}{*}{ Virus } & \multirow[t]{2}{*}{ Strain } & \multirow[t]{2}{*}{ Host } & \multirow{2}{*}{$\begin{array}{l}\text { Collection } \\
\text { date }\end{array}$} & \multirow{2}{*}{$\begin{array}{l}\text { Geographical } \\
\text { location }\end{array}$} & \multirow[t]{2}{*}{ Habitat } & \multicolumn{3}{|c|}{ GenBank ID } \\
\hline & & & & & & NS5 & $E$ & prM \\
\hline JEV & $\begin{array}{l}\text { TC2G5_18-8E-Y-T- } \\
\text { CXt-Y-5-19 }\end{array}$ & $\begin{array}{l}\text { Culex tritaeniorhyn- } \\
\text { chus }\end{array}$ & 6-Aug-2018 & $\begin{array}{l}\text { Fuyu village, Beihai } \\
\text { township }\end{array}$ & Cattle farm & MT254428 & MT254462 & MT254450 \\
\hline JEV & $\begin{array}{l}\text { TC2F12_18-8E-Y-T- } \\
\text { CXt-Y-5-30 }\end{array}$ & Cx. tritaeniorhynchus & 6-Aug-2018 & $\begin{array}{l}\text { Fuyu village, Beihai } \\
\text { township }\end{array}$ & Cattle farm & MT254429 & & \\
\hline JEV & $\begin{array}{l}\text { TC2F6_18-8E-Y-T- } \\
\text { CXt-Y-5-35 }\end{array}$ & Cx. tritaeniorhynchus & 6-Aug-2018 & $\begin{array}{l}\text { Fuyu village, Beihai } \\
\text { township }\end{array}$ & Cattle farm & MT254430 & MT254463 & MT254451 \\
\hline JEV & $\begin{array}{l}\text { TC2H11_18-8E-Y-T- } \\
\text { CXt-Y-5-44 }\end{array}$ & Cx. tritaeniorhynchus & 6-Aug-2018 & $\begin{array}{l}\text { Fuyu village, Beihai } \\
\text { township }\end{array}$ & Cattle farm & MT254431 & MT254464 & MT254452 \\
\hline JEV & $\begin{array}{l}\text { TC2A1_18-8 M-Y-T- } \\
\text { CXt-Y-5-8 }\end{array}$ & Cx. tritaeniorhynchus & 14-Aug-2018 & $\begin{array}{l}\text { Fuyu village, Beihai } \\
\text { township }\end{array}$ & Cattle farm & MT254432 & & \\
\hline JEV & $\begin{array}{l}\text { TC2B4_18-8 M-Y-T- } \\
\text { CXt-Y-5-10 }\end{array}$ & Cx. tritaeniorhynchus & 14-Aug-2018 & $\begin{array}{l}\text { Fuyu village, Beihai } \\
\text { township }\end{array}$ & Cattle farm & MT254433 & MT254465 & MT254453 \\
\hline JEV & $\begin{array}{l}\text { TC1H10_18-8 M-Y- } \\
\text { T-Cxt-Y-5-11 }\end{array}$ & Cx. tritaeniorhynchus & 14-Aug-2018 & $\begin{array}{l}\text { Fuyu village, Beihai } \\
\text { township }\end{array}$ & Cattle farm & MT254434 & MT254466 & MT254454 \\
\hline JEV & $\begin{array}{l}\text { TC2B10_18-8 M-Y- } \\
\text { T-CXt-Y-5-21 }\end{array}$ & Cx. tritaeniorhynchus & 14-Aug-2018 & $\begin{array}{l}\text { Fuyu village, Beihai } \\
\text { township }\end{array}$ & Cattle farm & MT254435 & & MT254455 \\
\hline JEV & $\begin{array}{l}\text { TC1H8_18-8 M-Y-T- } \\
\text { CXt-Y-5-25 }\end{array}$ & Cx. tritaeniorhynchus & 14-Aug-2018 & $\begin{array}{l}\text { Fuyu village, Beihai } \\
\text { township }\end{array}$ & Cattle farm & MT254436 & & MT254456 \\
\hline JEV & $\begin{array}{l}\text { TC4B3_18-9E-Y-T- } \\
\text { CXt-Y-5-7 }\end{array}$ & Cx. tritaeniorhynchus & 5-Sep-2018 & $\begin{array}{l}\text { Fuyu village, Beihai } \\
\text { township }\end{array}$ & Cattle farm & MT254437 & & \\
\hline JEV & $\begin{array}{l}\text { TC4E10_18-9E-Y-T- } \\
\text { CXt-Y-5-11 }\end{array}$ & Cx. tritaeniorhynchus & 5-Sep-2018 & $\begin{array}{l}\text { Fuyu village, Beihai } \\
\text { township }\end{array}$ & Cattle farm & MT254438 & MT254467 & MT254457 \\
\hline JEV & $\begin{array}{l}\text { TC4C11_18-9E-Y-T- } \\
\text { CXt-Y-5-12 }\end{array}$ & Cx. tritaeniorhynchus & 5-Sep-2018 & $\begin{array}{l}\text { Fuyu village, Beihai } \\
\text { township }\end{array}$ & Cattle farm & MT254439 & MT254468 & MT254458 \\
\hline JEV & $\begin{array}{l}\text { TC4E7_18-9E-Y-T- } \\
\text { CXt-Y-5-21 }\end{array}$ & Cx. tritaeniorhynchus & 5-Sep-2018 & $\begin{array}{l}\text { Fuyu village, Beihai } \\
\text { township }\end{array}$ & Cattle farm & MT254440 & & MT254459 \\
\hline JEV & $\begin{array}{l}\text { TC4D5_18-9E-Y-T- } \\
\text { CXt-Y-5-28 }\end{array}$ & Cx. tritaeniorhynchus & 5-Sep-2018 & $\begin{array}{l}\text { Fuyu village, Beihai } \\
\text { township }\end{array}$ & Cattle farm & MT254441 & MT254469 & MT254460 \\
\hline JEV & $\begin{array}{l}\text { TC4A5_18-9L-Y-T- } \\
\text { CXt-Y-5-1 }\end{array}$ & Cx. tritaeniorhynchus & 27-Sep-2018 & $\begin{array}{l}\text { Fuyu village, Beihai } \\
\text { township }\end{array}$ & Cattle farm & MT254442 & MT254470 & MT254461 \\
\hline YNCXFV & $\begin{array}{l}\text { TC2H8_18-8E-Y-T- } \\
\text { CXt-Y-5-17 }\end{array}$ & Cx. tritaeniorhynchus & 6-Aug-2018 & $\begin{array}{l}\text { Fuyu village, Beihai } \\
\text { township }\end{array}$ & Cattle farm & MT254443 & & \\
\hline YNCXFV & $\begin{array}{l}\text { TC4C9_18-9E-Y-T- } \\
\text { Cxt-Y-5-18 }\end{array}$ & Cx. tritaeniorhynchus & 5-Sep-2018 & $\begin{array}{l}\text { Fuyu village, Beihai } \\
\text { township }\end{array}$ & Cattle farm & MT254444 & & \\
\hline CTFV & $\begin{array}{l}\text { TC2B9_18-8 M-Y-T- } \\
\text { CXV-Y-5-1 }\end{array}$ & CX.vagans & 14-Aug-2018 & $\begin{array}{l}\text { Fuyu village, Beihai } \\
\text { township }\end{array}$ & Cattle farm & MT254445 & & \\
\hline AeFV & $\begin{array}{l}\text { TC4E2_18-9E-Y-T- } \\
\text { Aea-B-JM-1 }\end{array}$ & Aedes aegypti & 5-Sep-2018 & $\begin{array}{l}\text { Changdong com- } \\
\text { munity, Tengyue } \\
\text { town }\end{array}$ & $\begin{array}{l}\text { Suburb residential } \\
\text { area }\end{array}$ & MT254446 & & \\
\hline AeFV & $\begin{array}{l}\text { TC4A8_18-9L-Y-T- } \\
\text { Aea-B-1-1 }\end{array}$ & Ae. aegypti & 27-Sep-2018 & $\begin{array}{l}\text { Changdong com- } \\
\text { munity, Tengyue } \\
\text { town }\end{array}$ & $\begin{array}{l}\text { Suburb residential } \\
\text { area }\end{array}$ & MT254447 & & \\
\hline YDFV & $\begin{array}{l}\text { TC2A6_18-8 M-Y-T- } \\
\text { Anp-Y-2-1 }\end{array}$ & Cx.pseudovihnui & 14-Aug-2018 & $\begin{array}{l}\text { Tiancheng com- } \\
\text { munity, Tengyue } \\
\text { town }\end{array}$ & Hospital & MT254448 & & \\
\hline ISFV & $\begin{array}{l}\text { TC3D4_18-7 M-Y-T- } \\
\text { Ans-Y-5-11 }\end{array}$ & Anopheles sinensis & 17-Jul-2018 & $\begin{array}{l}\text { Fuyu village, Beihai } \\
\text { township }\end{array}$ & Cattle farm & MT254449 & & \\
\hline
\end{tabular}

AeFV Aedes flavivirus, CTFV Culex theileri flavivirus, JEV Japanese encephalitis virus, NS5 non-structural 5 gene, E envelope gene, prM pre-membrane gene, YDFV Yamadai flavivirus, YNCXFV Yunnan Culex flavivirus

E129 (Thr $\rightarrow$ Met), E222 (Ala $\rightarrow$ Ser), E327 $(\mathrm{Ser} \rightarrow \mathrm{Thr})$, E366 $($ Ala $\rightarrow$ Ser), E433 (Val $\rightarrow$ Ile), no differences were observed in key amino acid sites related to antigenicity.
We compared the deduced amino acid sequences of the whole-genome between TC4E10_18-9E-Y-T-CxtY-5-11 and DH10M978 strain, and there were four non-synonymous changes distributed in each capsid 
$\left(\mathrm{C},{ }^{127} \mathrm{Thr} \rightarrow \mathrm{Ala}\right)$, pre-membrane $\left(\mathrm{prM},{ }^{128} \mathrm{Met} \rightarrow \mathrm{Ile}\right), \mathrm{E}$ $\left({ }^{727} \mathrm{Val} \rightarrow\right.$ Leu), and non-structure 1 (NS1, ${ }^{822} \mathrm{Trp} \rightarrow$ Cys) proteins. Seventy-eight substitutions were observed between the TC4E10_18-9E-Y-T-Cxt-Y-5-11 strain and the SA14-14-2 strain (Additional file 1: Table S3), distributed in $\mathrm{C}$ (5 positions), prM (5 positions), E (15 positions), NS1 (15 positions), NS2A (6 positions), NS2B (4 positions), NS3 (8 positions), NS4A (6 positions), and NS5 (14 positions) proteins. No change was detected in the NS4B region of the viral protein. Among TC4E10_189E-Y-T-Cxt-Y-5-11, DH10M978, SA14-14-2, and SA strains, three amino acid substitutions were found to be unique in the TC4E10_18-9E-Y-T-Cxt-Y-5-11 strain, including ${ }^{128} \mathrm{Met} \rightarrow \mathrm{Ile},{ }^{727} \mathrm{Val} \rightarrow$ Leu, and ${ }^{822} \mathrm{Trp} \rightarrow$ Cys.

\section{Sequence analysis and phylogenetic characterization of ISFVs}

Sixty-eight partial NS5 sequences of 30 representative flavivirus that were retrieved from GenBank and the 22 described here were aligned. As shown in Fig. 2, all the lineages, including individuals representing the same ISFV, formed a distinct lineage with a high bootstrap value. The lineages were host-specific in general and the seven newly obtained ISFVs from Tengchong were distributed in five lineages.

The Yamadai flavivirus (YDFV) was detected in $C x$. pseudovihnui (MT254448), distributed in Tiancheng Community, Tengchong County. Analysis of their partial NS5 sequence fragments revealed 91.5-91.9\% similarity with the YDFVs sequences (LC513840, and AB981186) from $C x$. tritaeniorhynchus collected from Japan that is available in GenBank. Two strains of Yunnan Culex flavivirus (YNCxFV, MT254443, and MT254444) were found in two pools of $C x$. tritaeniorhychus, sharing $92.4 \%$ sequence similarity. Based on the short NS5 sequence fragments, the nucleotide similarity between the newly obtained YNCxFV strains and the YNCxFV from Lushui County, Yunnan Province (NC_021069) was 91.5-95.0\%, while it was $81.9-87.7 \%$ with QBVs available in GenBank. In the NS5 tree (Fig. 2), the YNCxFV sequences formed a sister lineage to the group containing QBV sequences with a moderate bootstrap value $(64 \%$ by Bayesian method). A Culex theileri flavivirus (CTFV) strain was detected in a pool of $C x$. vagans. It shares $90.8 \%$ similarity in nucleotide sequence with the CTFV strain from Portugal (HE574573). In the NS5 tree, several sequences, previously identified as Culex flavivirus (CxFV) (MH827522, MF582373, MF582377, and MF582380) and mosquito flavivirus (KY247170, KX652377, and KX652378) were gathered in the CTFV lineage. The new CTFV stain shared 90.2-92.3\% nucleotide sequence similarity with other CTFV sequences. The CTFV lineage was close with the cluster, which was combined with lineages of YNCxFVs, YDFVs, and QBVs. Two Ae. albopictus pools were positive for AeFV. They (MT254446, and MT254447) shared 98.9\% nucleotide sequence similarity and were most related to La Tina virus (KY320649) with 96.9-97.3\% similarity. They were gathered with other AeFVs in the NS5 tree. A new detected flavivirus strain from a pool of An. sinensis shared $93.5 \%$ similarity with the Flaviviridae sp. from Phlebotomus sp. (MN090154) in $157 \mathrm{nt}$ of NS5 gene, and lower than $69.6 \%$ nucleotide sequence similarity and $71.3 \%$ amino acid sequence similarity with its most similar mosquito flavivirus isolate OccaFV3 (GQ476995). In the phylogenetic tree, the two strains (MT254449, and MN090154) formed a monophyletic lineage, supported by high bootstrap value, and distant from other Anopheles specific flaviviruses. Their nucleotide sequence similarity with other ISFVs was below the threshold proposed by Kuno et al. [56], who defined the species as a class of viruses with a nucleotide sequence similarity higher than $84 \%$. These results suggest that AAFV is probably a new member of the ISFV family.

\section{The infection rate of flavivirus in culicines}

All the JEV-positive sequences were obtained from $C x$. tritaeniorhynchus pools. The overall infection rate (Table 2) according to bias-corrected MLE and MIR of JEV in Cx. tritaeniorhynchus, with 95\% confidence intervals $(C I)$ were $2.4(1.4-3.9)$ and $2.3(1.1-3.5)$ per 1000 individuals, respectively. JEVs were detected in samples collected in August and September, and no JEV-positive pools were found in July and October. The bias-corrected MLE of JEV infection rates were 3.0 (1.5-5.6), and 3.9 (1.6-8.2) per 1000 Cx. tritaeniorhynchus in August and September, respectively. The bias-corrected MLE of YNCxFV, YDFV, AeFV, and AAFV, expressed as the number of infected mosquitoes per 1000 individuals, for Cx. tritaeniorhynchus, Cx. pseudovihnui, Ae. albopictus, and An. sinensis were 0.3 (0.1-1.0), 7.6 (1.4-69.3), 41.4 (9.3-127.0), and 0.4 (0.0-1.7), respectively.

\section{Discussion}

The newly detected JEV Tengchong strains showed low genetic diversity in NS5, prM, and $E$ genes, and were most closely related to the strain from the local area in 2010, suggesting that frequent transmission of JEV GI-b sub-genotype occurred in Tengchong. The GI genotype was isolated from Yunnan in 1977 and 1982 [57]. Considering the $E$ gene tree, these belonged to the GI-a sub-genotype (Fig. 3). However, the GI genotype had not been detected in Yunnan since then until GI-b subgenotype was isolated in 2007 [58]. The GI-a sub-genotype was once prevalent in tropical Asia in the 1970s and 1980s [57, 59]. Few strains of the GI-a sub-genotype has 
Table 2 Bias Corrected Maximal likelihood estimation (MLE) and minimum infection rate (MIR) of flaviviruses during mosquito activity season of Tengchong in 2018

\begin{tabular}{llllllll}
\hline $\begin{array}{l}\text { Detected } \\
\text { virus }\end{array}$ & Host & $\begin{array}{l}\text { No. of } \\
\text { individuals }\end{array}$ & $\begin{array}{l}\text { No. of } \\
\text { positive } \\
\text { pools }\end{array}$ & $\begin{array}{l}\text { No. of } \\
\text { pools }\end{array}$ & $\begin{array}{l}\text { Positive } \\
\text { pool rate } \\
\text { (\%) }\end{array}$ & $\begin{array}{l}\text { Bias corrected MLE (95\% } \\
\text { Cl) }\end{array}$ & MIR (95\% Cl) \\
\hline JEV & Culex tritaeniorhynchus & 6490 & 15 & 149 & 10.07 & $2.44(1.43-3.94)$ & $2.31(1.14-3.48)$ \\
YNCXFV & CX. tritaeniorhynchus & 6490 & 2 & 149 & 1.34 & $0.31(0.06-1.01)$ & $0.31(0.00-0.74)$ \\
AeFV & Aedes albopictus & 43 & 2 & 7 & 28.57 & $41.43(9.30-127.70)$ & $46.51(0.00-109.46)$ \\
YDFV & CX.pseudovihnui & 50 & 1 & 2 & 50.00 & $7.62(1.35-69.27)$ & $20.00(0.00-58.81)$ \\
AAFV & Anopheles sinensis & 2775 & 1 & 145 & 0.69 & $0.36(0.02-1.74)$ & $0.36(0.00-1.07)$ \\
\hline
\end{tabular}

AeFV Aedes flavivirus, Cl confidence interval, JEV Japanese encephalitis virus, YDFV Yamadai flavivirus, YNCXFVYunnan Culex flavivirus

been detected after that. Recently, it has been detected in humans (2015) and mosquitoes (2014) in Cambodia [60]. In addition, the GIII circulated in Yunnan between 1978 and 2004 as the predominant genotype but has not been found in recent years [58]. This coincides with the replacement of GIII of JEV by GI in several Asian countries during the past few decades [61, 62], whereas GIII was found using a neutralization test among the laboratory-confirmed JE cases in Myanmar in 2013 [63]. Further clarification using additional samples is required to determine if GIII co-circulates with GI in Tengchong.

There were no corresponding mutations at the E107, E138, E176, E177, E264, E279, E315 or E439 loci of the newly obtained strains, which are related to virus attenuation [54]. However, six amino acid residues in the newly detected JEV Tengchong strains differed from those in the vaccine SA14-14-2-derived strain. Also, the co-evolution of two pairs of sites within GIs (residues S89N to F360Y and M129T to I141V) was not observed in the new Tengchong strains, in which these residues functionally interact with each other to maintain a functional $\mathrm{E}$ protein [61]. Twelve combinations of amino acids, with SKSS and NKSS as dominant ones, were observed at four sites in the E protein (E123, E209, E227 and E408), which were defined based on the predicted positive selections [64]. NKSS is the sole haplotype presented in the newly obtained strains. SKSS haplotype was observed in strains collected in 2007 from Tengchong (KT957420, KU295056, and KU295060). Notably, more JEV sequences involved in recent JEV outbreaks [7, 65, 66] contain the SKSS haplotype.

The annual morbidity and mortality of JE were 0.75/100 000, and 5.6\%, respectively, in Yunnan Province, with an increase in adult JE incidences [67]. The introduction of JE vaccines in China since the 1970s, and the following intervention of intensive JE vaccine program in children have dramatically decreased JE cases [68]. However, JE outbreaks occurred occasionally in China [5-8] and other countries in Southeast Asia [69, 70], with the increase in adult cases. Irrigated rice production and pig rearing are the two main factors inducing the circulation of JEV in nature. In this study, all the JEV-positive pools were collected in Fuyu Village, mainly in August and September in 2018, coinciding with the peak of the JE incidence in Yunnan [67]. The bias-corrected MLE of JEV infection rates in September reached 3.9 with 8.2 as the upper limit per 1000 individuals. The infection rate was high in the courtyards of farmers' households with pigsties (7.4 per 10 000) in Shanxi, which is located in the epidemic area of adult JE cases [5, 66]. The MLE of JEV was 11.8 per $1000 \mathrm{Cx}$. tritaeniorhynchus during the 2010 JE outbreak in Korea [71]. The prevalence of flavivirus, e.g. WNV (data unavailable for JEV) that represents an "epidemic risk" is more than 5 per 1000 mosquitoes [7], indicating that the Fuyu Village has a potential epidemic risk. The aerial view of the Fuyu Village showed the village to be characterized by a rural environment with dense housing, with a large paddy field nearby (Fig. 1b). The collection site of flavivirus-positive pools was a cattle farm, but domestic pigpens were distributed sporadically nearby. In addition, there was a pig farm $2 \mathrm{~km}$ away from the cattle farm. The natural and social environment was suitable for the transmission of JEV in the Fuyu Village. Notably, cattle are dead-end host, and Culex mosquitoes preferentially feed on cattle. The cattle can be used to divert infected mosquitoes from humans and swine [72]; however, it reflects JEV prevalence in the local area.

As JE is under the umbrella of the vaccine program, the JEV vaccine, included in the Expand Program of Immunization in China since 2008, free of charge, was implemented in children with a coverage of almost $100 \%$ in Tengchong. However, there exists the possibility that for a few infants, the immunization time was postponed, as their parents worked abroad. From 2017 to 2019, JE clinical cases were not observed in Tengchong reported by the officials at the Tengchong County Disease Prevention and Control. However, we cannot exclude the 
possibility of JE cases with asymptomatic or mild symptoms, since JEV infection is symptomatic in less than $1 \%$ of the cases [73]. Considering the high infection rate of JEV in mosquitoes, it is wise to carry out a baseline survey to detect the coverage of JEV antibodies in the serum of local residences, who are lacking vaccination. The vaccination strategy in adults could be established and conducted according to the infectious risk estimated by the results of the baseline survey. Moreover, segregation of livestock farms away from human residential areas is suggested to prevent the spread of JEV from animal reservoir to human population. Besides, the surveillance on the dynamics of JEV infection in mosquitoes is essential to predict the epidemic risk of JEV outbreak in the local area. Moreover, with the promotion of the Belt and Road Initiative, imported cases-following the increase in border business trade and travel-should be monitored more closely to prevent secondary incidences (the infection of a local population from an imported case).

ISFVs are a type of flavivirus, propagating only in mosquito cells, unable to replicate in mammalian cells [74]. Several novel flaviviruses have been isolated and characterized as ISFVs in this century, and documented around the globe [38, 75-80]. To our knowledge, there is no record of the presence and diversity of ISFVs in Tengchong. Infection with CxFV can increase the insect's vector competence for WNV, as reported in field and laboratory tested $C x$. tritaeniorhynchus $[81,82]$. Other studies showed that earlier infection of ISFVs suppresses subsequent replication of mosquito-borne flaviviruses associated with human diseases [83, 84]. Five kinds of ISFVs were found in Tengchong, and no pools were coinfected with both ISFVs and JEVs, implying possibility of the existence of superinfection exclusion between ISFVs and vertebrate-infecting flaviviruses. However, all JEVpositive pools of $C x$. tritaeniorhynchus contained YDFV in Yamaguchi, Japan, in 2013 [85]. Thus, more evidence is required to address whether ISFV-infected mosquitoes can escape vector competence or superinfection exclusion for pathogenic flavivirus infections.

In general, ISFVs are the host genus or species-specific by vertical transmission [86]. YDFV were previously isolated from Japan in pools of $C x$. tritaeniorhynchus with the infection rate of 1.8 per 1000 individuals (MIR) [85]. Whereas, it was present in one of two pools of Cx. pseudovihnui, and absent in Cx. tritaeniorhynchus pools. In addition, the CTFV was firstly isolated from samples collected from An. vagus pool in Indonesia, collected in 1981 [87]. Recently, it was also found in Guangdong Province, China ([88], Cx. quinquefasciatus, 2013), Myanmar ([89], Cx. tritaeniorhynchus, Cx. vishnui, Cx. fuscocephalus, 2014), and Turkey ([90], Cx. theileri, 2015); it was detected in a pool of $C x$. vagans in
Tengchong, China. Interestingly, CTFV was previously identified in Cx. tritaeniorhynchus samples, collected in Portugal, in 2009 [91]. This indicates that the ISFVs have probably circulated in nature for a long time, and have wide geographic and host ranges, although with a short history of discovery. The new YNCxFV strain from one pool of Cx. tritaeniorhynchus was closely related to the other two YNCxFV strains (MT254443, and MT254444), from Lushui County, approximately $180 \mathrm{~km}$ away from Tengchong. To date, these were the only three strains of YNCxFV available on GenBank, and no other records were reported in other places, except the Yunnan Province. AeFVs were detected in two out of seven $A e$. albopictus pools with the infection rate of 41.4 per 1000 individuals (bias-corrected MLE). It was higher than what was detected in the Songjiang District, Shanghai, in 2016 (33.9 per 1000 individuals) [38]. The AAFV from $A n$. sinensis were far distant from the lineage of AnFVs. The other strain (MN090154) was isolated from Phlebotomus sp. in Bosnia and Herzegovina, collected in the same year. Precisely $92.9 \%$ nucleotide similarity and $100 \%$ amino acid similarity were observed between the two strains in the highly conserved NS5 gene, and below the cutoff value (84\%) among species of flavivirus with their close relatives (OcFVs), which was $69.6 \%$. It's a pity that we failed to amplify longer sequences in NS5 and $E$ genes of AAFV. Moreover, the most diverse and prevalent ISFV, CxFV, mainly hosted in Cx. pipiens complex, was not detected in $C x$. pipiens quinquefasciatus in this study. The CxFVs can be divided into two genotypes. One is prevalent in Asia and the United States and is mainly detected in Cx. pipiens pipens, the other is distributed in Africa, the Caribbean, and Latin America, sharing the same host $C x$. pipiens quinquefasciatus [92]. The latter was found in the Middle East region recently, while the genotype of $\mathrm{CxFV}$ in $\mathrm{Cx}$. pipiens quinquefasciatus populations in Asia has not been found yet.

The main limitation of our study is that the supernatants of mosquito homogenate viruses were not cultivated in mosquito or human cell lines. The low concentration or titer of a given virus in mosquito homogenates may have influenced the results of pathogen detection and amplification of long sequence. Additional virus-positive pools might have been missed by direct RNA isolation and thus, the actual infection rate of arboviruses in Tengchong may be underestimated. Furthermore, as the JE potential epidemic focus we detected here was in a cattle farm, which is the dead-end host, we need to analyze arbovirus in mosquitoes collected in a pig farm near the cattle farm to see the infection rate of JEV in the amplifying host. Also, the taxonomy of the tentatively named AAFV has not been resolved. The evidence proposing AAFV as a novel species of ISFV was not 
sufficient. It is crucial to isolate the virus in cell culture, obtain its whole-genome, electron microscopy of virion particles, the cytopathic effect, and perform neutralization tests to clarify the taxonomic status of the species further.

\section{Conclusions}

A potential JE epidemic focus was detected with the high JEV infection rate in the field-caught mosquitoes in Tengchong. The phylogenetic analyses showed that the 15 strains of newly detected JEV belong to the GI-b genotype, similar to the strain found in Tengchong in 2010. It indicates a possible JEV epidemic in the local area. Notably, all the JEV-positive pools were collected in a cattle farm in the Fuyu Village, which is surrounded by dense residential housing, domestic pigpens, and intensified irrigated rice paddies. It is necessary to implement the immunization program for children persistently, and investigate the number of adults who are not inoculated with the JE vaccine in local area. In addition, moving all domestic pigs into a communal piggery at a location more than $5 \mathrm{~km}$ away from the human population could help reduce the risk of JE transmission to humans. Moreover, five species of ISFVs, AeFV, CTFV, YDFV, YNCxFV, and AAFV were found co-circulating in Tengchong. This is the first record of ISFVs in this area. The results strongly suggest the need for widespread and sustained mosquito-based arbovirus surveillance in local areas. It allows accurate and timely estimations of the actual disease burden and prevalence of JE and other mosquitoborne pathogens.

\begin{abstract}
Abbreviations
AAFV: Anopheles-associated flavivirus; AeFV: Aedes flavivirus; AnFV: Anopheles flavivirus; Cl: Confidence interval; CTFV: Culex theileri flavivirus; CxFV: Culex flavivirus; E: Envelope gene; JEV: Japanese encephalitis virus; NS5: Non-structural 5 gene; PAFV: Phlebotomus associated flavivirus; prM: Pre-membrane gene; QBV: Quang Binh flavivirus; OcFV: Ochlerotatus caspius flavivirus; WNV: West Nile virus; YDFV: Yamadai flavivirus; YNCxFV: Yunnan Culex flavivirus.
\end{abstract}

\section{Supplementary Information}

The online version contains supplementary material available at https://doi. org/10.1186/s40249-021-00838-z.

Additional file 1: Fig. S1. Phylogenetic tree generated by Bayesian analysis of Japanese encephalitis virus pre-membrane gene sequences; Table S1. Primer sets used for sequencing the JEV TC4E10_18-9E-Y-TCXt-Y-5-11 strain; Table S2. Primer sets used for sequencing the AeFV TC4A8_18-9L-Y-T-Aea-B-1-1 strain; Table S3. Comparison on amino acid substitutions among JEV TC4E10_18-9E-Y-T-CXt-Y-5-11 strain, DH10M978 strain, vaccine strain SA14-14-2, and SA14 strain.

Acknowledgements

Not applicable.

\section{Authors' contributions}

YF, SL and YZ designed the study; X-SL, JW, SY, X-HL and SL conducted the field collections; YF and WZ carried out laboratory experiments, performed phylogenetic analyses; YF wrote the original manuscript; SL, JX and YZ revised the manuscript and gave approval for its publication. All authors read and approved the final manuscript.

\section{Funding}

The Special Foundation of Basic Science and Technology Resources Survey of Ministry of Science and Technology of China (Grant No. 2017FY101203), the Project of Basic Platform of National Science and Technology Resources of the Ministry of Sciences and Technology of China (No. TDRC-2019-194-30).

\section{Availability of data and materials}

All data generated or analysed during this study are included in the published article and Additional file.

\section{Declarations}

Ethics approval and consent to participate

Not applicable.

\section{Consent for publication}

Not applicable.

\section{Competing interests}

The authors declare that the research was conducted in the absence of any commercial or financial relationships that could be construed as a potential conflict of interest.

\section{Author details}

${ }^{1}$ National Institute of Parasitic Diseases, Chinese Center for Disease Control and Prevention (Chinese Center for Tropical Diseases Research); NHC Key Laboratory of Parasite and Vector Biology; WHO Collaborating Centre for Tropical Diseases; National Center for International Research on Tropical Diseases, Shanghai, China. ${ }^{2}$ School of Global Health, Chinese Center for Tropical Diseases Research, Shanghai Jiao Tong University School of Medicine, Shanghai, China. ${ }^{3}$ Tengchong County Center for Disease Control and Prevention, Tengchong, Yunnan, China. ${ }^{4}$ Zichuan District Center for Disease Control and Prevention, Shandong, Zibo, China.

Received: 10 November 2020 Accepted: 8 April 2021

Published online: 26 April 2021

References

1. Zhang F, Zhao H, Li L, Jiang T, Hong W, Wang J, et al. Severe dengue outbreak in Yunnan, China, 2013. Int J Infect Dis. 2014;27:4-6.

2. Xiao J, He J, Deng A, Lin H, Song T, Peng Z, et al. Characterizing a large outbreak of dengue fever in Guangdong Province China. Infect Dis Poverty. 2016;5:44.

3. Han L, Yu X, Guan S, Hou W, Wang Y, Zheng L, et al. The epidemiological and clinical features of 403 cases with dengue fever in Fuzhou City. Chin J Infect Dis. 2018;36:411-6. (in Chinese)

4. Yan H, Ding Z, Yan J, Yao W, Pan J, Yang Z, et al. Epidemiological characterization of the 2017 dengue outbreak in Zhejiang, China and molecular characterization of the viruses. Front Cell Infect Microbiol. 2018;8:216.

5. Wang L, Fu S, Wang H, Liang X, Cheng J, Jing $H$, et al. Japanese encephalitis outbreak, Yuncheng, China, 2006. Emerg Infect Dis. 2007;13:1123-5.

6. Hu Q, Chen B, Zhu Z, Tian J, Zhou Y, Zhang X, et al. Recurrence of Japanese encephalitis epidemic in Wuhan, China, 2009-2010. PLoS One. 2013;8:e52687.

7. Tao Z, Liu G, Wang M, Wang H, Lin X, Song L, et al. Molecular epidemiology of Japanese encephalitis virus in mosquitoes during an outbreak in China, 2013. Sci Rep. 2014;4:4908.

8. Tian Y, Yang L. Epidemiological situation of Japanese encephalitis in Oinzhou District, Tianshui, Gansu Province, during 2016-2018. Chin J Vector Biol Control. 2019;30:232. (in Chinese) 
9. China applies to WHO for malaria eradication certification. http://www. xinhuanet.com/english/2020-12/11/c_139582585.htm. Accessed 7 Feb 2021.

10. Wu D, Wu J, Zhang Q, Zhong H, Ke C, Deng X, et al. Chikungunya outbreak in Guangdong Province, China, 2010. Emerg Infect Dis. 2012;18:493.

11. Kindhauser MK, Allen T, Frank V, Santhana RS, Dye C. Zika: the origin and spread of a mosquito-borne virus. Bull World Health Organ. 2016;94:675

12. Fu S, Song S, Liu H, Li Y, Li X, Gao X, et al. Zika virus isolated from mosquitoes: a field and laboratory investigation in China, 2016. Sci China Life Sci. 2017;60:1364-71.

13. Song S, LiY, Fu S, Liu H, Li X, Gao X, et al. Could zika virus emerge in Mainland China? Virus isolation from nature in Culex quinquefasciatus, 2016 Emerg Microbes Infect. 2017;6:1-3.

14. Xiao P, Han J, Zhang Y, Li C, Guo X, Wen S, et al. Metagenomic analysis of Flaviviridae in mosquito viromes isolated from Yunnan Province in China reveals genes from dengue and zika viruses. Front Cell Infect Microbiol. 2018;8:359.

15. Dong $X$, Zhou H, Gong Z. Mosquito classification in Yunan Province. Kunming: Yunnan Scientific \& Technical Publishers; 2010. (in Chinese)

16. Dong $X$, Zhou H, Gong Z, Dong L, Wang X. Investigation of mosquito species in Yunnan Province with some new species. Chin J Vector Biol Control. 2004;15:186-8. (in Chinese)

17. Deng S, Zhang H, Li J. Distribution characteristics of mosquito and their natural infection with Japanese encephalitis virus in Yunnan Province. Chin J Vector Biol Control. 2019;20:344-8. (in Chinese)

18. Zhang $H$, Zhang $Y$, Yang W, Feng $Y$, Nasci RS, Yang J, et al. Mosquitoes of Western Yunnan Province, China: seasonal abundance, diversity, and arbovirus associations. PLoS One. 2013;8:1

19. Feng Y, Fu S, Zhang H, Li M, Zhou T, Wang J, et al. Distribution of mosquitoes and mosquito-borne viruses along the China-Myanmar border in Yunnan Province. Jpn J Infect Dis. 2012;65:215-21.

20. Liang G-D, Li X-H, Gao X-Y, Fu S-H, Wang H-Y, Li M-H, et al. Arboviruses and their related infections in China: A comprehensive field and laboratory investigation over the last 3 decades. Rev Med Virol. 2018;28:e1959.

21. Yang D, Xu C, Wang J, Zhao Y. Spatiotemporal epidemic characteristics and risk factor analysis of malaria in Yunnan Province, China. BMC Public Health. 2017;17:66.

22. Clements ACA, Barnett AG, Cheng ZW, Snow RW, Zhou HN. Spacetime variation of malaria incidence in Yunnan Province, China. Malar J. 2009;8:180.

23. Hui F, Xu B, Chen Z, Cheng X, Liang L, Huang H, et al. Spatio-temporal distribution of malaria in Yunnan Province, China. Am J Trop Med Hyg. 2009:81:503-9.

24. Liu K, Hou X, Wang Y, Sun J, Xiao J, Li R, et al. The driver of dengue fever incidence in two high-risk areas of China: a comparative study. Sci Rep. 2019:9:19510

25. Yin S, Feng J, Xia S, Zhang L, Xia Z, Zhou S, et al. Epidemiological analysis of imported malaria cases in 20 countries at border region of Yunnan Province form 2012 to 2014. Zhongguo Xue Xi Chong Bing Fang Zhi Za Zhi. 2016;28:252-7. (in Chinese)

26. Wang J, Zhang H, Sun $X$, Fu S, Wang H, Feng $Y$, et al. Distribution of mosquitoes and mosquito-borne arboviruses in Yunnan Province near the China-Myanmar-Laos border. Am J Trop Med Hyg. 2011:84:738-46.

27. Wang B, Li Y, Feng Y, Zhou H, Liang Y, Dai J, et al. Phylogenetic analysis of dengue virus reveals the high relatedness between imported and local strains during the 2013 dengue outbreak in Yunnan, China: a retrospective analysis. BMC Infect Dis. 2015;15:142.

28. Wang J, Yin S, Li S, Li X, Feng J. Epidemiological analysis of local malaria transmission in Tengchong City from 2000 to 2015. Chin J Trop Dis Parasitol. 2016;14:152-4. (in Chinese)

29. Wang J, Yin S, Li X, Tang Z. Epidemiological analysis of imported malaria in Tengchong City from 2013 to 2016. Chin J Trop Dis Parasitol. 2017;15:935. (in Chinese)

30. Li S, Yin S, Wang J, Li X, Feng J. Shifting from control to elimination: analysis of malaria epidemiological characteristics in Tengchong County around China-Myanmar border, 2005-2014. Malar J. 2016:15:45.

31. Lu R, Yin J, Lin Y, Guo H, Li Z, Peng X, et al. Analysis on the epidemiological characteristics of imported infectious diseases in Yunnan border area from 2013 to 2017. Morden Prev Med. 2018;45:2505-8.

32. Feng $Y$, Li S, Zhang H, Fu S, Kang $X$, Cun S, et al. Molecular characterization of Japanese encephalitis virus and Getah virus strains newly isolated in Tengchong County, Yunnan Province China. Chin J Zoonoses. 2014;30:353-7. (in Chinese)

33. Zha B, Zhou H, Zhang H, Liang G. Investigation of mosquitoes and mosquito-borne arboviruses in Yunnan Province, China in 1975-2010. Chin J Vector Biol Control. 2012;23:439-44. (in Chinese)

34. Li X, Li S, Wang J, Feng J, Wang X, Wu J, et al. Analysis on mosquito survey in Tengchong of Yunnan from 2012 to 2013. Chin J Vector Biol Control. 2016;27:398-401. (in Chinese)

35. Liu Q, Liu X, Woodward A, Bai L, et al. Mosquitoes established in Lhasa city, Tibet China. Parasit Vectors. 2013;6:224.

36. WHO \&TDR. Dengue: guildlines for diagnosis, treatment, prevention and control. Geneva: World Health Organization; 2009.

37. Lu B. Fauna Sinica. Insect Vol. 8, Diptera: Culicidae 1. Beijing: Science Press; 1997. (in Chinese)

38. Fang Y, Zhang Y, Zhou Z, Shi W, Xia S, Li Y, et al. Co-circulation of Aedes flavivirus, Culex flavivirus, and Quang Binh virus, in Shanghai China. Infect Dis Poverty. 2018;7:75

39. Hoffmann PR, Woodrow RJ, Calimlim PS, Sciulli RH, Effler PV, Miyamoto $\checkmark$, et al. West Nile virus surveillance: a simple method for verifying the integrity of RNA in mosquito (Diptera: Culicidae) pools. J Med Entomol. 2004:41:731-5.

40. Li M, Xia Z, Tang L. Establishment and application of multiplex PCR system for detecting four human Plasmodium species. Zhongguo Ji Sheng Chong Xue Yu Ji Sheng Chong Bing Za Zhi. 2015;33:91-5. (in Chinese)

41. Cook S, Moureau G, Harbach RE, Mukwaya L, Goodger K, Ssenfuka F et al. Isolation of a novel species of flavivirus and a new strain of Culex flavivirus (Flaviviridae) from a natural mosquito population in Uganda. J Gen Virol. 2009;90:2669-78.

42. Scaramozzino N, Crance JM, Jouan A, Debriel DA, Stoll F, Garin D. Comparison of flavivirus universal primer pairs and development of a rapid, highly sensitive heminested reverse transcription-PCR assay for detection of flaviviruses targeted to a conserved region of the NS5 gene sequences. J Clin Microbiol. 2001;39:1922-7.

43. Gao X, Liu H, Wang H, Fu S, Guo Z, Liang G. Southernmost Asia is the source of Japanese encephalitis virus (genotype 1) diversity from which the viruses disperse and evolve throughout Asia. PLoS Negl Trop Dis. 2013;7:e2459.

44. Wang H, Takasaki T, Fu S, Sun X, Zhang H, Wang Z, et al. Molecular epidemiological analysis of Japanese encephalitis virus in China. J Gen Virol. 2007:88:885-94.

45. Bryant JE, Crabtree MB, Nam VS, Yen NT, Duc HM, Miller BR. Isolation of arboviruses from mosquitoes collected in northern Vietnam. Am J Trop Med Hyg. 2005;73:470-3.

46. Kuno G, Mitchell CJ, Chang GJ, Smith GC. Detecting bunyaviruses of the Bunyamwera and California serogroups by a PCR technique. J Clin Microbiol. 1996:34:1184-8.

47. BlastN. https://blast.ncbi.nlm.nih.gov/Blast.cgi?PROGRAM=blastn\&PAGE TYPE=BlastSearch\&LINK_LOC=blasthome. Accessed 13 March 2021.

48. Larkin MA, Blackshields G, Brown NP, Chenna R, McGettigan PA McWilliam $H$, et al. Clustal W and Clustal X version 2.0. Bioinformatics. 2007;23:2947-8.

49. Kimura M. A simple method for estimating evolutionary rates of base substitutions through comparative studies of nucleotide sequences. J Mol Evol. 1980;16:111-20.

50. Kumar S, Stecher G, Tamura K. MEGA7: molecular evolutionary genetics analysis version 7.0 for bigger datasets. Mol Biol Evol. 2016;33:1870-4.

51. Posada D, Crandall KA. MODELTEST: testing the model of DNA substitution. Bioinformatics. 1998;14:817-8.

52. Wilgenbusch JC, Swofford D. Inferring evolutionary trees with PAUP* . Curr Protoc Bioinformatics. 2003;6(6):4.

53. Ronquist F, Teslenko M, van der Mark P, Ayres DL, Darling A, Hohna S, et al. MrBayes 3.2: efficient Bayesian phylogenetic inference and model choice across a large model space. Syst Biol. 2012;61:539-42.

54. Biggerstaff BJ. PooledlnfRate, version 3.0: a Microsoft ${ }^{\circledR}$ Excel ${ }^{\circledR}$ add-in to compute prevalence estimates from pooled samples. CDC: Fort Collins; 2006.

55. Zhang S, Zhou S, Zhou Z, Chen T, Wang X, Shi W, et al. Monitoring of malaria vectors at the China-Myanmar border while approaching malaria elimination. Parasit Vectors. 2018:11:511.

56. Kuno G, Chang GJ, Tsuchiya KR, Karabatsos N, Cropp CB. Phylogeny of the genus Flavivirus. J Virol. 1998;72:73-83. 
57. Wang J, Zhang H, Zhou J, Liang G. Genotyping of Japanese encephalitis viruses isolated in Yunnan. Chin J Exp Clin Virol. 2008;22:87-90. (in Chinese)

58. Feng Y, Zhang H, Yang W, Zhang Y, Huang L, Deng S, et al. Molecular epidemiology of Japanese encephalitis viruses isolated in Yunnan Province, 1977-2010. Chin J Epidemiol. 2016;137:1519-25. (in Chinese)

59. Carney J, Daly JM, Nisalak A, Solomon T. Recombination and positive selection identified in complete genome sequences of Japanese encephalitis virus. Arch Virol. 2012;157:75-83.

60. Duong V, Choeung R, Gorman C, Laurent D, Crabol Y, Mey C, et al. Isolation and full-genome sequences of Japanese encephalitis virus genotype I strains from Cambodian human patients, mosquitoes and pigs. J Gen Virol. 2017;98:2287-96.

61. Schuh AJ, Ward MJ, Brown AJL, Barrett ADT. Dynamics of the emergence and establishment of a newly dominant genotype of Japanese encephalitis virus throughout Asia. J Virol. 2014;88:4522-32.

62. Do LP, Bui TM, Phan NT. Mechanism of Japanese encephalitis virus genotypes replacement based on human, porcine and mosquito-originated cell lines model. Asian Pac J Trop Med. 2016;9:333-6.

63. Kyaw AK, Ngwe Tun MM, Nabeshima T, Buerano CC, Ando T, Inoue S, et al. Japanese encephalitis- and dengue-associated acute encephalitis syndrome cases in Myanmar. Am J Trop Med Hyg. 2019;100:643-6.

64. Han N, Adams J, Chen P, Guo ZY, Zhong XF, Fang W, et al. Comparison of genotypes I and III in Japanese encephalitis virus reveals distinct differences in their genetic and host diversity. J Virol. 2014;88:11469-79.

65. Lee D-W, Choe YJ, Kim JH, Song KM, Cho H, Bae G-R, et al. Epidemiology of Japanese encephalitis in South Korea, 2007-2010. Int J Infect Dis. 2012;16:e448-52.

66. Ren X, Fu S, Dai P, Wang H, Li Y, Li X, et al. Pigsties near dwellings as a potential risk factor for the prevalence of Japanese encephalitis virus in adult in Shanxi China. Infect Dis Poverty. 2017;6:100.

67. Zhu Q, Hu X, Li Q, He L, Li H, Tang T, et al. Epidemiological characteristics of Japanese encephalitis in Yunnan Province 2005-2015. Chin J Vaccines Immunol. 2017;23:52-7. (in Chinese)

68. Gao X, Li X, Li M, Fu S, Wang H, Lu Z, et al. Vaccine strategies for the control and prevention of Japanese encephalitis in Mainland China, 1951-2011. PLoS Negl Trop Dis. 2014;8:e3015.

69. Oo PM, Hlaing T, Lwin S, Pittyawonganon C, Sirichaisinthop J. A large outbreak of Japanese encephalitis in Rakhine State, Myanmar: implication for vaccine policy. Outbreak Surveill Investig Rep. 2016;9:8-15.

70. Easton A. Outbreak of Japanese encephalitis hits Malaysia. BMJ. 1999;318:893.

71. Seo HJ, Kim HC, Klein TA, Ramey AM, Lee JH, Kyung SG, et al. Molecular detection and genotyping of Japanese encephalitis virus in mosquitoes during a 2010 outbreak in the Republic of Korea. PLoS One. 2013:8:e55165.

72. Solomon T. Control of Japanese encephalitis - within our grasp? N Engl J Med. 2006;355:869-71.

73. Chen H, Chang J, Tang R. Current recommendations for the Japanese encephalitis vaccine. J Chin Med Assoc. 2015;78:271-5.

74. Cook S, Moureau G, Kitchen A, Gould EA, De Lamballerie X, Holmes EC, et al. Molecular evolution of the insect-specific flaviviruses. J Gen Virol. 2012;93:223-34.

75. Hoshino K, Isawa H, Tsuda Y, Sawabe K, Kobayashi M. Isolation and characterization of a new insect flavivirus from Aedes albopictus and Aedes flavopictus mosquitoes in Japan. Virology. 2009;391:119-29.

76. Moureau G, Ninove L, Izri A, Cook S, De Lamballerie X, Charrel RN. Flavivirus RNA in Phlebotomine sandflies. Vector Borne Zoonotic Dis. 2010;10:195-7.
77. Kim DY, Guzman H, Bueno R Jr, Dennett JA, Auguste AJ, Carrington CV, et al. Characterization of Culex flavivirus (Flaviviridae) strains isolated from mosquitoes in the United States and Trinidad. Virology. 2009;386:154-9.

78. Crabtree MB, Nga PT, Miller BR. Isolation and characterization of a new mosquito flavivirus, Quang Binh virus, from Vietnam. Arch Virol. 2009;154:857-60.

79. Vazquez A, Sanchez-Seco MP, Palacios G, Molero F, Reyes N, Ruiz S, et al Novel flaviviruses detected in different species of mosquitoes in Spain. Vector Borne Zoonotic Dis. 2012;12:223-9.

80. Cook S, Chung BYW, Bass D, Moureau G, Tang S, Mcalister E, et al. Novel virus discovery and genome reconstruction from field RNA samples reveals highly divergent viruses in dipteran hosts. PLoS One. 2013;8:e80720

81. Kent RJ, Crabtree MB, Miller BR. Transmission of West Nile virus by Culex quinquefasciatus Say infected with Culex flavivirus Izabal. PLoS Negl Trop Dis. 2010;4:e671.

82. Newman CM, Cerutti F, Anderson TK, Hamer GL, Walker ED, Kitron UD, et al. Culex flavivirus and West Nile virus mosquito coinfection and positive ecological association in Chicago United States. Vector Borne Zoonotic Dis. 2011:11:1099-105.

83. Hobsonpeters J, Yam AWY, Lu J, Setoh YX, May FJ, Kurucz N, et al. A new insect-specific flavivirus from northern Australia suppresses replication of West Nile virus and Murray Valley encephalitis virus in co-infected mosquito cells. PLoS ONE. 2013;8:1.

84. Goenaga S, Kenney JL, Duggal NK, Delorey MJ, Ebel GD, Zhang B, et al. Potential for co-infection of a mosquito-specific flavivirus, Nhumirim Virus, to block West Nile virus transmission in mosquitoes. Viruses. 2015;7:5801-12.

85. Kuwata R, Sugiyama H, Yonemitsu K, Nguyen D, Terada Y, Taniguchi M et al. Isolation of Japanese encephalitis virus and a novel insect-specific flavivirus from mosquitoes collected in a cowshed in Japan. Arch Virol. 2015;160:2151-9.

86. Cook S, Bennett S, Holmes E, De Chesse R, Moureau G, de Lamballerie X Isolation of a new strain of the flavivirus cell fusing agent virus in a natural mosquito population from Puerto Rico. J Gen Virol. 2006;87:735-48.

87. Sadeghi M, Popov VL, Guzman H, Phan TG, Vasilakis N, Tesh RB, et al. Genomes of viral isolates derived from different mosquitos species. Virus Res. 2017:242:49-57.

88. Wu D, Li B, Tan Q, Zhang X, Zhang H, Cao Y, et al. Identification and phylogenetic analyses of three strains of mosquito flavivirus from Guangdong Province China. Chin J Virol. 2019;35:240-6. (in Chinese)

89. Kyaw Kyaw A, Tun MMN, Buerano CC, Nabeshima T, Sakaguchi M, Ando T, et al. Isolation and genomic characterization of Culex flaviviruses from mosquitoes in Myanmar. Virus Res. 2018;247:120-4.

90. Ergunay K, Litzba N, Brinkmann A, Gunay F, Kar S, Oter K, et al. Isolation and genomic characterization of Culex theileri flaviviruses in field-collected mosquitoes from Turkey. Infect Genet Evol. 2016:46:138-47.

91. Parreira R, Cook S, Lopes A, de Matos AP, de Almeida AP, Piedade J, et al. Genetic characterization of an insect-specific flavivirus isolated from Culex theileri mosquitoes collected in Southern Portugal. Virus Res. 2012;167:152-61.

92. Bittar C, Machado DC, Vedovello D, Ullmann LS, Rahal P, Junior JPA, et al. Genome sequencing and genetic characterization of Culex flavirirus (CxFV) provides new information about its genotypes. Virol J. 2016;13:158. 